\title{
Main Trends in the Development of R\&D and Higher Qualification Faculty Training Department at Tambov State Technical University
}

\author{
D.Yu. Muromtsev
}

\author{
Vice-Rector for Research and Innovation Activities, \\ Tambov State Technical University, \\ 106, Sovetskaya St., Tambov, 392000, Russia
}

Tel.: +7 (4752) 6301 41. E-mail: postmaster@nauka.tstu.ru

\begin{abstract}
A brief historical overview is given and an assessment is made of the current state of the Department of Research \& Development and Higher Qualification Faculty Training at the Federal State Budgetary Educational Institution of Higher Education "Tambov State Technical University" (hereinafter TSTU). Basic trends in modernization of the department are described and major growth points of research and technical potential of TSTU in the areas of new materials and nanotechnologies, energy efficiency and energy resource saving, radio electronics and instrument engineering, chemical engineering, biotechnology and technology of food and processing industry, construction, and housing and public utilities sector are presented.
\end{abstract}

\section{Keywords}

R\&D department; infrastructure; growth points; performance indicators; activity; development trends; higher qualification faculty.

\section{Introduction}

Tambov State Technical University (TSTU) was established in 1958 as Tambov Branch of Moscow Institute of Chemical Engineering to satisfy the needs of intensively developing chemical and chemical engineering industries in our country. The choice of Tambov for organizing a new institute was not random, since in the 1940s - 1950s the industrial production, including chemical engineering, was rapidly developing in the Tambov region.

From the very start, alongside with educational activity, Tambov Branch was involved in active research work. In 1963, Research \& Development (R\&D) department was organized on a voluntary basis to perform studies including those which met the demands of industrial enterprises.

In 1965, the Branch acquired the status of an independent institution and was transformed into Tambov Institute of Chemical Engineering (TIKHM). In 1966, in TIKHM in accordance with the Decree
No. 96 of December 22, 1966 of the Ministry of Higher and Secondary Special Education of the RSFSR, R\&D department was set up to organize and carry out research and development work.

In 1980, by the Decree of the Board of the Ministry of Higher and Secondary Special Education of the USSR, Department of Postgraduate Studies was organized in TIKHM and the first enrollment on specialties: "Machines and aggregates of oil refining and chemical industries", "Automation of technological processes and industries", "Processes and devices of chemical technology" was made. In 1982, Specialized Dissertation Council for Ph.D. theses defense on specialty 05.17 .08 - Processes and devices of chemical technology - began its work.

Over the next 20 years, a modern educational and methodological, research, material and technical base for training highly qualified specialists has been built in TIKHM. Powerful scientific and pedagogical schools have evolved, which enabled TIKHM to obtain the status of State Technical University in 1993. 


\section{Science and Innovations in TSTU Today}

At present, TSTU is focused on the implementation of the programs of research, innovation and education activities in the fields of new materials and nanotechnologies, biotechnology, technospheric security, rational environmental management and environmental protection; energy and resource saving, chemical engineering, information systems and sustainable development through an open and growing network of educational and scientific complexes.

The university employs highly qualified faculty: seven Honored Workers of Science (and Technology) of the Russian Federation, six Honored Inventors of Russia, 10 Laureates of the State Prize and the Prize of Government of the Russian Federation in Science and Technology for Young Scientists, two Laureates of the Prize of Government of the Russian Federation in Education, 95 doctors and 365 candidates of science.

University faculty members are trained in 22 areas (44 profiles), among which 13 areas (29 profiles) belong to the priority areas of development of science, technology and techniques. The number of postgraduate students, doctoral students and persons admitted to prepare and defend their theses in 2016 amounts to 250 people.

Currently, five Specialized Dissertation Councils for Ph.D. theses defense on nine research programs work at the university. In addition, the university takes part in the work of the three joint Specialized

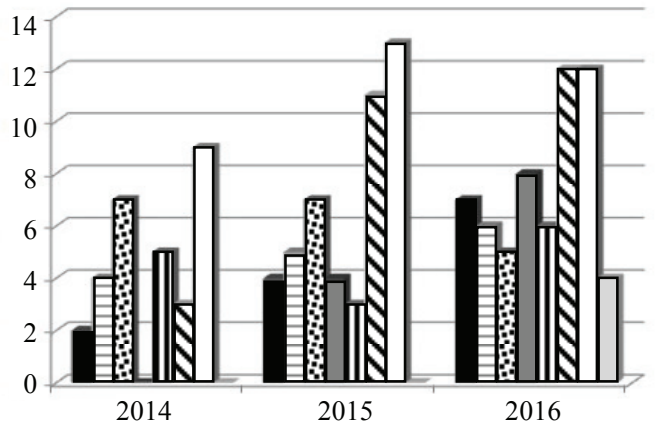

Fig. 1. Number of defenses in Dissertation Councils:

-D 212.260.01; 目-D 212.260.02; 图 - D 212.260.05;

-D 212.260.06; 而-D 212.260.07; $\mathbf{\nabla}$-DM 212.261.08; - DM 220.041.03; $\square$ - D 999.080.03

Dissertation Councils for theses defense for Doctor's and Ph.D. degrees (Fig. 1). The last of the mentioned joint Dissertation Councils - D 999.080.03 - was opened on the basis of Tambov, Voronezh and Saratov State Technical Universities by the Decree of the Ministry of Education and Science of RF of June 22, 2016, No. 749 on the programs 051608 Nanotechnologies and nanomaterials (technical sciences), 020021 - Chemistry of the solid body (chemical sciences).

In 2016, 60 theses were defended in the Dissertation Councils of the TSTU, including 10 theses for a degree of Doctor of Sciences.

The infrastructure of the department of research and development and higher qualification faculty training is shown in Fig. 2.

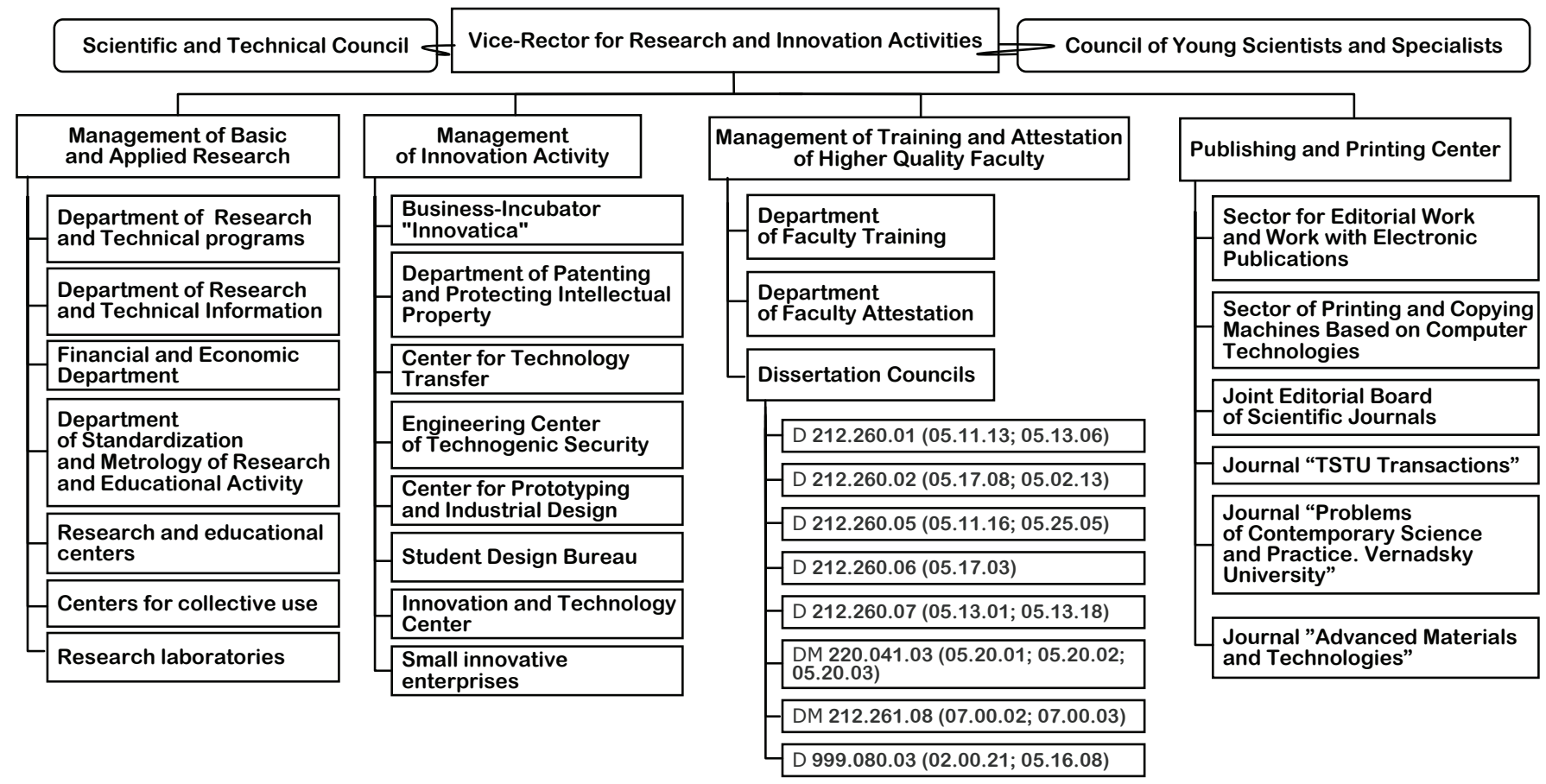

Fig. 2. Elements of the infrastructure of the Department of Research \& Development and Higher Qualification Faculty Training at TSTU 
It includes:

- research and educational centers (RECs), set up jointly with RAS institutes: REC "Nanotechnologies and New Materials" with the Institute of Problems of Chemical Physics; REC "Development of New Science-Intensive Technologies for Effective Use of Products of Recycled and Utilized Technogenic Formations and Wastes for Autonomous Power Supply" with the Joint Institute for High Temperatures; REC "Biomedical Technologies of Life Support and Human Protection" with the Institute of Biomedical Problems; REC "Informatics, Distributed Computing and Computer Networks" with the Institute of System Analysis; REC "New Solid-Phase Chemical Technologies" with the Institute of Structural Macrokinetics and Materials Science Problems;

- centers for the collective use of unique scientific equipment: "Obtaining and using Multifunctional Nanomaterials" and "Radio Electronics and Communication";

- technology transfer center;

- branch research laboratories;

- prototyping and industrial design center;

- basic departments "Agroengineering" (set up on the basis of FSBSI VNIITiN); "Engineering of nanotechnologies" (set up on the basis of $\mathrm{AO}$ "Zavkom") and "Functional materials and life support systems" (set up on the basis of OAO "Corporation" Roskhimzashchita");

- specialized innovation and technology centers;

- business-incubator "Innovatica";

- student design office;

- small innovative enterprises that facilitate to commercialize the results of intellectual activity, including 'Nanohalvanica', 'Innovation Center for Information Technologies', 'Innovative Chemical Technologies and Products', "Ecotechnology", "Pure Energy", "Energonanotech", and others.

Only in the recent three years the university has carried out large-scale projects within the framework of the implementation of Decree No. 218 of April 9, 2010 of the Government of the Russian Federation "Measures of State Support for the Development of Cooperation between Russian Educational Organizations of Higher Education, State Research Institutions and Organizations Realizing Comprehensive Projects for Setting up High-Tech Production" and the federal target program "Research and Development in Priority Areas of Research and Technological Complex of Russia for 2014-2020 years" [1,2]. Research and development work has been performed, processing developments have been carried out and the production of polyfunctional nanomaterials and superconcentrates, based on them, has started to be used in advanced structural polymers and composites of a new generation (jointly with OAO "Zavkom"), poly-fuel heat-generating systems have been developed on local and renewable fuel resources (jointly with OAO "Prodmash"), the models and algorithms for information support of technical vision systems are being developed for quality control of agricultural plant produce (jointly with AO "NPO" Androidnaya tekhnika"). The amount of research projects in the implementation part of these projects amounted to more than 330 million rubles.

The amount of funding of basic and applied research, and developments is shown in Fig. 3.

Basic and applied research is carried out in priority areas of science, technology and techniques in the Russian Federation:

- nanosystems industry;

- information and telecommunication systems;

- energy efficiency, energy saving and nuclear energy engineering;

- rational nature management.

Being financially supported by the Russian Science Foundation, the Russian Foundation for Basic Research and the Russian Humanitarian Scientific Foundation, the university is carrying out basic research aimed at gaining new knowledge and scientific findings: "Improvement of the Physico-Mechanical Properties of Polymer Composites when Carbon Nanomaterials are Introduced into the Polymer Matrix"; "Development of Theoretical Foundations to Create a Research Basis for the Systems of Protecting Human Respiratory Organs from the Damaging Factors of Chemical and Biological Nature"; "Development of an Integrated Method for Diagnosing and Evaluating the Genesis of Cerebral Aneurysms when FluxControlling Stents are Installed Using Endoscopic Optical Coherent Tomography and Individualized High-Precision Mathematical Modeling of Cerebral Hemodynamics"; "The Outstanding People of "Democratic Socialism" in the Context of the Political Culture of Russian Society in the First Quarter of the 20th Century"; "The Peasantry in the Conditions of Modernization and Destruction of Traditional Values: Social Deviations of the late XIX - early XX century (regional aspect)," etc. Only in 2016 the amount of fundamental research of the university amounted to 55.9 million rubles.

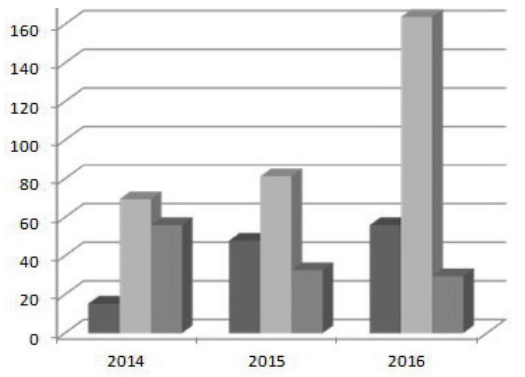

Fig. 3. R\&D funding, mln. rub.:

basic research; _ - applied research; - developments 


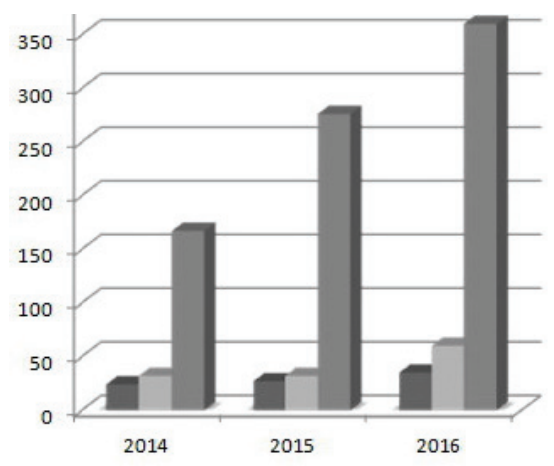

Fig. 4. Publication activity of the university's faculty: - WoS publications; - Scopus publications; - RSCI publications

Particular attention is paid to the issues of increasing the publication activity and scientometric indicators of the university's faculty (Fig. 4 and 5).

At present, the university's faculty have an access to the RSCI, Scopus and the Web of Science databases.

TSTU regularly acts as a host at international scientific and scientific-technical events: "International Thermophysical School"; scientific-practical conferences "V.I. Vernadsky: Sustainable Development of the Region"; "Graphene and Related Structures: Synthesis, Production and Application"; "Virtual Modeling, Prototyping and Industrial Design"; conference with elements of a research school "Actual Problems of Energy Saving and Efficiency in Technical Systems", etc.

According to the monitoring of higher education institutions, conducted by the Ministry of Education and Science of the Russian Federation, in 2015, the research activity of the university was assessed by an integral indicator characterizing the amount of $R \& D$ funding per one faculty member, which amounted to 250.3 thousand rubles for TSTU, with a threshold value of 51.3 thousand rubles. The picture of evaluation of various aspects of research and innovation activity is as follows (Fig. 6).

The indicator names, measurement units and indicator values are given in Table 1.

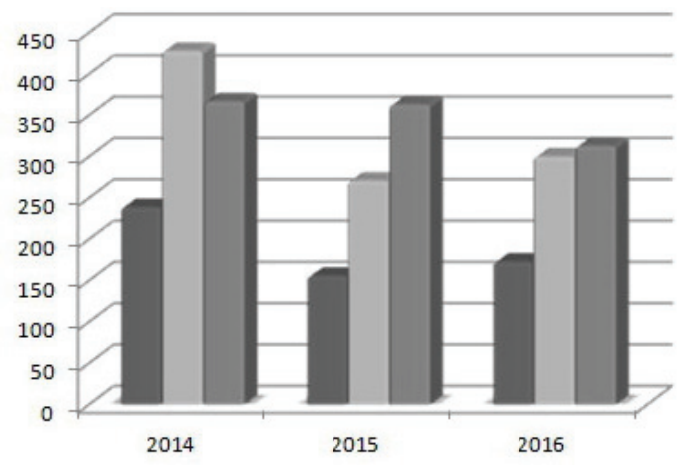

Fig. 5. University's faculty publication citing: - WoS citing; - Scopus citing; - RSCI citing per 100 faculty members

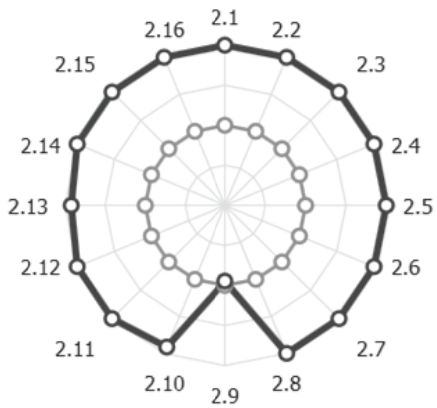

Fig. 6. Monitoring indicators of research and innovation activities of the university: $-\infty-$ median indicator values of state and municipal universities; $-0-$ performance indicators

\section{Modernization of the Department of Research \& Development and Higher Qualification Faculty Training}

Modernization of research and innovation activities of TSTU is intended to increase the competitiveness of the regional innovation system of the Tambov region through conducting promising fundamental and applied research, breakthrough technology transfer, providing the university and high technology industries with highly qualified staff, as well as international cooperation with leading research and educational centers. It will enable developing the research, technical and human potential of the university and the region, expand the range of knowledge-intensive services, organize a center for generating unique competences, develop network integration with leading universities in the country, research institutes of the Russian Academy of Sciences, partner-enterprises and innovation infrastructure facilities.

Modernization of research and innovation activities of TSTU is aimed at implementing the Decree of the President of the Russian Federation No. 642 of December 1, 2016 "On the Strategy of Research and Technological Development of the Russian Federation" [3]. The Decree provides for research and technological development of the Russian Federation the transformation of science and technology into a key factor in the competitiveness of the Russian Federation, the formation of priority areas for the development of science, technology and techniques, and the increased effectiveness of research and developments, and practical application of the results.

The main promising areas of modernization of research and innovation activities (growth points) of the research and technical potential of the university and the region are:

- new materials and nanotechnologies: synthesis of catalysts for chemical processes for obtaining various modifications of carbon (fullerenes, graphenes, carbon nanotubes of the "Taunit" series, etc.); modification of existing and production of new 
Indicators for monitoring research and innovation activities

\begin{tabular}{|c|c|c|c|}
\hline № & Indicator name & $\begin{array}{l}\text { Measurement } \\
\text { unit }\end{array}$ & $\begin{array}{l}\text { Indicator } \\
\text { value }\end{array}$ \\
\hline 2.1 & $\begin{array}{l}\text { The number of citations of publications published over the past } 5 \text { years, indexed in the } \\
\text { information-analytical system of scientific citation Web of Science, per } 100 \text { faculty members }\end{array}$ & unit & 48.98 \\
\hline 2.2 & $\begin{array}{l}\text { The number of citations of publications published over the past } 5 \text { years, indexed in the } \\
\text { scientific citation information system Scopus, per } 100 \text { faculty members }\end{array}$ & unit & 73.09 \\
\hline 2.3 & $\begin{array}{l}\text { The number of citations of publications published over the past } 5 \text { years, indexed by the } \\
\text { Russian Scientific Citation Index (hereinafter referred to as RSCI), per } 100 \text { faculty members }\end{array}$ & unit & 1094.45 \\
\hline 2.4 & $\begin{array}{l}\text { The number of publications of the organization indexed in the information-analytical } \\
\text { system of scientific citation Web of Science, per } 100 \text { faculty members }\end{array}$ & unit & 9.49 \\
\hline 2.5 & $\begin{array}{l}\text { The number of publications of the organization indexed in the information-analytical } \\
\text { system of scientific citation Scopus, per } 100 \text { faculty members }\end{array}$ & unit & 13.29 \\
\hline 2.6 & $\begin{array}{l}\text { The number of publications of the organization indexed in the information-analytical } \\
\text { system of scientific citation RSCI, per } 100 \text { faculty members }\end{array}$ & unit & 307.36 \\
\hline 2.7 & The total $\mathrm{R} \& \mathrm{D}$ volume & $\begin{array}{l}\text { thousand } \\
\text { rubles }\end{array}$ & 131862.50 \\
\hline 2.8 & The share of $\mathrm{R} \& \mathrm{D}$ in the total income of the educational organization & $\%$ & 14.70 \\
\hline 2.9 & $\begin{array}{l}\text { The share of } R \& D \text { performed by internal researchers (without involvement of external } \\
\text { researchers) in the total income of the educational organization from } R \& D\end{array}$ & $\%$ & 94.55 \\
\hline 2.10 & $\begin{array}{l}\text { Income from R\&D (excluding budgetary funds of the budgetary system of the Russian } \\
\text { Federation, state funds for supporting science), per one faculty member }\end{array}$ & $\begin{array}{l}\text { thousand } \\
\text { rubles }\end{array}$ & 128.60 \\
\hline 2.11 & The number of license agreements & unit & 3.00 \\
\hline 2.12 & $\begin{array}{l}\text { The share of funds obtained by the educational organization from the use of the results of } \\
\text { intellectual activity in the total income of the educational organization }\end{array}$ & $\%$ & 0.18 \\
\hline 2.13 & $\begin{array}{l}\text { The share of the faculty members without a degree at the age under } 30 \text {, candidates of } \\
\text { science - under } 35 \text {, doctors of sciences - under } 40 \text { in the total number faculty members }\end{array}$ & $\%$ & 30.64 \\
\hline 2.14 & $\begin{array}{l}\text { The share of faculty members who defended candidate and doctoral dissertations during } \\
\text { the reporting period in the total number of the faculty }\end{array}$ & $\%$ & 3.63 \\
\hline 2.15 & $\begin{array}{l}\text { The number of scientific journals, including electronic ones, published by the educational } \\
\text { organization }\end{array}$ & unit & 4.00 \\
\hline 2.16 & The number of grants received during the reporting year, per 100 faculty members & unit & 7.78 \\
\hline
\end{tabular}

composite materials using nanocarbon additives; development of technology and equipment for producing nanomaterials; application of nanomaterials in various industries, construction, and agriculture.

It is planned to set up pilot-industrial production of polyfunctional nanomaterials and superconcentrates, based on them, to be used in perspective structural polymers and composites of a new generation. The work is carried out within the framework of RF Government Decree No. 218 of April 9, 2010 "On Measures of State Support for the Development of Cooperation of Russian Educational Organizations of Higher Education, State Research Institutions and Organizations Implementing Comprehensive Projects for setting up High-Tech Manufacture, as part of the subprogram" Institutional Development of Research Sector" of the State program of the Russian Federation "Development of Science and Technology" for 2013-2020".

Jointly with Italian scientists, fundamental research is being conducted in "Controlling the Shape and Oscillations of Adaptive Thin-Walled Structures with Segmented Sensors and Actuators from Functional Piezoelectric Materials Based on Three-Dimensional Geometrically Precise Finite Shell Elements."

- energy efficiency and energy resource saving: development of power plants using renewable energy sources, including those obtained by utilization of technogenic formations, agricultural and poultry waste; energy saving management of technological processes; energy efficiency of transportation, conversion 
and energy consumption systems; development of supercapacitors based on graphene electrodes.

Jointly with OAO "Prodmash" (city of Rostov-onDon), a project is underway to develop technical solutions for the creation of polyfuel heat-generating systems on local and renewable fuel resources.

- radio electronics and instrument engineering: development of information-sensory systems for mechatronics and robotics, technical and information support for the control and management of product quality, production, processes and services; development of methods and systems of information security; development of methods and devices for radioelectronic warfare; ensuring information security in information systems for various purposes.

Jointly with AO "NPO "Androidnaya Tekhnika" (city of Magnitogorsk), models and algorithms for information support of technical vision systems for quality control of agricultural plant produce are developed.

Research is being done on the topic: "Development of an Integrated Method for Diagnosing and Evaluating the Genesis of Cerebral Aneurysms when Flux-Controlling Stents are Installed Using Endoscopic Optical Coherent Tomography and Individualized High-Precision Mathematical Modeling of Cerebral Hemodynamics".

- chemical engineering: development of methodology for predicting and ensuring the reliability of the processes and devices of chemical manufacture; modeling and optimization in chemical technology; development of the theory and methods of computeraided design of complex technical systems; technology and life support systems and respiratory protecting equipment against the negative impact of technogenic and natural character;

-processing of agricultural products and biotechnology: development of technology and techniques for increasing the efficiency of the region's agro-industrial complex; development of bioengineering technology, food and processing industry; modern methods of processing and storage of agricultural products; obtaining environmentally friendly food for mass consumption and special purposes;

- construction, housing and public utilities sector: design, construction and upkeep of buildings using new energy-saving methods and technology; ecological safety of construction and municipal facilities and services; development of technology, organization of construction and maintenance of highways; development of new building materials and products from them; development of methods for assessing the noise level in buildings and adjacent areas for use in monitoring noise pollution of the environment and developing measures to reduce noise in urban areas.

Within the framework of these research areas, it is planned to increase the volume of R\&D for basic industries and high-tech sectors of the region's economy (chemical and radio electronic industry, power engineering, instrument engineering, agricultural machinery, biotechnology, information technology, construction, etc.).

As a result of modernization of research and innovation activities, the university will have an innovative ecosystem which will provide favorable conditions for transfer and commercialization of innovative technology and developments, will increase the competitiveness of science-intensive products, increase the volume of $\mathrm{R} \& \mathrm{D}$, science intensive and "culture intensive" services, mass engagement of graduates, post-graduates and faculty members in innovative and entrepreneurial activities.

Modernization of research and innovation activities is focused on the concept "University 3.0" and implies the implementation of the following strategic projects:

- innovative ecosystem as a factor of sustainable development of Tambov region;

- engineering of chemical machine-building and nanotechnologies;

- regional research and technical center "Agrobiotech";

- regional competences center for the defenseindustrial complex.

Innovative ecosystem as a factor of sustainable development of the region will create favorable conditions in the region for transfer and commercialization of innovative technology and developments. Development of the innovative ecosystem requires organizing a regional center to coordinate the implementation of $R \& D$ results at the high-tech enterprises in the region, developing a network of relevant innovation and technology centers and centers for collective use of unique equipment, the establishment of the center for generating unique competences in priority directions of development of the region, expansion of integration of innovative infrastructure of the university and the region and involvement of young people in an innovative and entrepreneurial activity.

Engineering of chemical machine-building and nanotechnology will create conditions for increasing the competitiveness of the region in the field of chemical engineering and nanoindustry. The center will promote the development of the existing and the formation of new research schools, the sustainable growth of R\&D participants in the field of chemical engineering and nanoindustry, the setting up of new and the development of existing research and educational centers and research laboratories to develop technology and equipment for chemical industry and produce functional and structural nanomaterials, improving the system of practice-oriented training of engineering and 
research staff for industrial enterprises of the region, the consolidation of the university research potential with the manufacturing facilities of high-tech enterprises. In order to create new respiratory protecting equipment against the negative impact of technogenic and natural character, it is planned to establish an engineering center "Technogenic safety and chemical engineering".

The regional research and technical center "Agrobiotech" will enable to increase the efficiency of the agro-industrial complex of the region through the technical and technological modernization of the enterprises of the industry, to create and develop the infrastructure necessary for the development and implementation of promising innovative projects for food and processing industries, to improve the system of practice-oriented training of engineering and research staff for the innovative development of the agro-industrial sector of the economy. The interaction between the regional research and technical center with the technological platform "Technology of the Food and Processing Industry of the Agro-Industrial Complex - Healthy Food Products" and enterprises of the agro-industrial complex will allow to more effectively solve the import substitution problem.

The regional center of competences for the defense-industrial complex will improve the content and technology of target faculty training and research and innovation developments in the interests of the organizations of the defense-industrial complex of the region, develop fundamental and applied research in the field of radio electronics and instrument engineering, information security through closer interaction with research structures of the RAS and creation of innovative developments aimed at improving the quality of products manufactured by enterprises of the defenseindustrial complex of the region. To ensure the implementation of research in the field of information technology and instrument engineering, it is planned to set up a center for collective use "Robototechnika".

\section{Conclusion}

The implementation of measures aimed at modernizing the department of research \& development and higher qualification faculty training will create favorable conditions for the technological development of the region, to form new leading scientific schools and promote successful careers of young researchers, increase the volume and improve the effectiveness of ongoing research, improve scientific reputation of the university in Russia and abroad, meet the region's needs for researchers in the key areas of the Tambov region and create conditions for the formation of a regional research and engineering elite.

The development of research and educational centers and research laboratories in priority areas of the region's development will contribute to enhancing the effectiveness of interaction between the university and academic sectors of science. The development of a system for support and promotion of research projects and scientific publications in the Russian and international research and educational space will increase the effectiveness of research.

Strengthening and development of relations with leading foreign research and educational institutions by developing and implementing mobility programs, retraining, faculty and research staff training at the leading research, industrial and educational centers and abroad, inviting leading foreign scientists to conduct research seminars and schools for young scientists, creation of scientific consortia and creative teams to participate in international scientific cooperation programs enhance the prestige of the university in the world scientific community.

The setting up of a regional center coordinating the implementation of $R \& D$ results at high-tech enterprises in the region will lead to the improved interaction between the elements within regional research and innovation infrastructure, enhancing the university's competitiveness, expanding the range of knowledge-intensive services and improving the quality of products manufactured at enterprises of the defense-industrial complex, chemical, food and processing industries.

The creation and development of the center for generating unique competencies based on modern technology, innovative processes and organization self-development mechanisms will make it possible to coordinate the activities of research teams taking into account the main prospective directions (growth points) of the development of the research and technical potential of the university and the region and to ensure an increase in revenues from the commercialization of intellectual activity results.

The development of the system of training and attestation of higher qualification faculty, the creation of conditions for steady functioning of existing Dissertation Councils and opening the new ones will ensure the reproduction of faculty potential capable of performing research and innovation projects at a high level.

\section{References}

1. Resolution of the Government of the Russian Federation No. 218 of April 9, 2010 "On Measures of State Support for the Development of Cooperation between Russian Educational Organizations of Higher Education, State Research Institutions and Organizations Realizing Complex Projects for Setting up HighTech Manufacture".

2. The federal target program "Research and Development in Priority Areas of Development of The Research and Technological Complex of Russia for 2014-2020".

3. The Decree of the President of the Russian Federation No. 642 of 01.12.2016 "On the Strategy of Research and Technological Development of the Russian Federation". 